\title{
On the Exploitation of Research Subjects
}

\section{Ken Kirkwood ${ }^{\star}$}

Faculty of Health Sciences, Western University, London, Ontario, Canada

\begin{abstract}
The issue of vulnerable populations in research is a highly contested one. The debate is highly charged and illuminative, but misguided in terms of its practical value. The error in much of the current debate involves trying to objectively define the subjective emotional experiences of individuals, and worse still, to create protections from this abstract standardization of individual experience. The purpose of vulnerability debates is about protecting those who are in no position to fully defend their interests from exploitation. Therefore the point of this article is to articulate the futility of operationalizing vulnerability and to instead focus on exploitation as the key moral variable in research ethics.
\end{abstract}

Keywords: Research ethics; Informed consent; Vulnerable populations; Bioethics; Clinical trials; Exploitation

\section{Introduction}

The $20^{\text {th }}$ century's long saga of exploited research subjects brought us to the apogee of scholarly backlash in the biomedical ethics literature by the end of that century. By the 1970s, the composite shadow cast by cases of research subject abuses known by the names Tuskegee, Nuremburg, Willow brook and McGill's Allan Memorial Institute, among many others [1], led scholars to make overly grand protectionist claims, defining enormous segments of the population as too prone to exploitation to be involved in research. For two examples, Hans Jonas offered the view all patients, described as the "vulnerable sick," are wrongly included in studies from which they might derive benefit [2]. Franz Ingelfinger made the most absolutist proscription in suggesting that he could find an element of coercion in every communication between researcher and subject [3].

This trend has reversed itself, and since the late 1990s, some streams of bioethical literature have gradually narrowed the definition of vulnerability beyond the point of having sufficient protectionist powers. The problem with the modern counter-movement is that it focuses all of its attention on the moral judgments we can make on the actions of researchers and has taken all of its focus off of the subjects. This paper suggests that the focus on vulnerability is mistaken in its efforts to protect through labeling large segments of the population. A more useful method would be to examine the wrongful behaviour namely exploitation - experienced by individuals who are vulnerable to and within research.

\section{$21^{\text {st }}$ Century Vulnerability}

Vulnerable populations are generally conceived of as people who susceptible or especially vulnerable to deception, manipulation, exploitation or harm [4]. It is true that we are all vulnerable is the broadest sense of the word; any life is fragile and a host of accidents or malicious or negligent acts by any number of unavoidable forces can extinguish it instantly. But when we speak of vulnerability in terms of research populations, we speak of an accentuated risk of harm-quite distinguishable from the vulnerability of the average person $[5,6]$.

Vulnerability can be viewed as of two fundamental kinds: intrinsic and extrinsic. One is intrinsically vulnerable when they lack the capacity to be autonomous due to injury or native incapacity, such as a neurological impairment. The other understanding of vulnerability is extrinsic, wherein a host of social or economic circumstances can convert otherwise secure individuals into vulnerable ones [7]. Kenneth
Kipnis has identified seven sources of vulnerabilities: capacitational, juridic, deferential, social, medical and allocation. Capacitational addresses questions of the subject's capacity to consent, juridic speak to the possible influence of an outside authority on the consent; deferential and social speak to individual sensitivities which may mitigate consent both on the individual basis (deferential) and with membership in historically-oppressed social groups (social). Medical is raised when the subject is recruited for participation precisely because he or she presents with an untreatable illness, which often overlaps with allocation, which sees a person without access to a social or public good being able to achieve it through research participation [8].

Through the regulatory articulations, there are many concerns about the imprecision in the use of the term 'vulnerable.' The American "common rule" identifies populations of potential research subjects who are 'vulnerable' (neonates, pregnant women, foetuses, prisoners and minors), but offers nothing in the way of defining what vulnerability is [9]. The recent revision to Canada's Tri-council Policy offers a more extensive taxonomy of vulnerable populations, and offers some applicable examples, but fails to define what vulnerability are [10]. While the policy does suggest that 'exclusion' of research participants could be utilized by researchers to avoid exploiting vulnerable subjects, the absence of an operationalization or algorithm leaves the decision to the conscience of the researcher who lacks coherent guidance on the issue.

The Council of International Organization of Medicine (CIOMS) offers us this definition: "those who are relatively (or absolutely) incapable of protecting their own interests. More formally, they may lack sufficient power, intelligence, education, resources, strength, or other needed attributes to protect their own interests"[11]. The problem here, as Levine et al. [12] noted, is that this definition captures some self-evident examples quite well but is overly broad, and thereby captures almost everyone by its definition, thus rendering it quite useless in defining less than obvious cases.

${ }^{*}$ Corresponding author: Ken Kirkwood, Assistant Professor, Faculty of Health Sciences, Western University, London, Ontario, Canada, Tel: 519-661-2111; E-mail: kkirko2@uwo.ca

Received July 26, 2012; Accepted November 15, 2012; Published November 24, 2012

Citation: Kirkwood K (2012) On the Exploitation of Research Subjects. J Clinic Res Bioeth 3:138. doi:10.4172/2155-9627.1000138

Copyright: @ 2012 Kirkwood K, et al. This is an open-access article distributed under the terms of the Creative Commons Attribution License, which permits unrestricted use, distribution, and reproduction in any medium, provided the original author and source are credited. 
Fundamentally the issue with all of the regulatory approaches, and many of the scholarly views, is that they attempt to define a profoundly subjective and existential quality from outside of the agent experiencing it.

\section{Tell Me How I Feel}

The perception that attempts to categorize vulnerability have failed is not surprising when we consider that the efforts have been directed towards the aims of social structures of research (e.g. funding agencies, research organizations, universities), and not towards the agents who experience vulnerability, and ultimately are most reliable experts in their own experience. The motivation for this definitional direction is a product of time and place; present-day clinical research in North America is a capital-intensive business with many partnerships between public and private interests. The concern for vulnerability in this context is to create a usable categorical definition to guide policy, regulation and enforcement of same to protect others who suffer from psychological or emotional states that diminish their autonomy [13]. An unintended side-effect of this approach is to dictate to the agent what the nature of their emotions are. This leaves us in a most absurd situation wherein people can feel (and therefore be) vulnerable, but fall outside the definition offered for the purposes of the governing social structure, and therefore their self-perception of vulnerability is deemed mistaken [14-16]. The analytical focus of the existing work on vulnerability has largely been directed towards the purposes of social structure, but in providing a working definition to that end, has denied the subject the validity of this most fundamentally personal experience. Ethically, it seems erroneous to objectively define subjective experiences when the definition is in service to the ethical regulation of behaviours of members of the research industry. Why seek to define my behaviour or existential state, when your purpose is to protect me from those who would seek to exploit that state? Furthermore the definition of that existential state can also have the effect of stigmatizing the population - viewing their ability to consent as relational to a researcher's paternalistic sensibilities. It seems more relevant to define and regulate the exploitative and unethical behaviours, rather than the susceptibility of others to it.

With this in mind, it seems that the evaluative focus of vulnerability should be redirected towards the definition and regulation of exploitation in research.

\section{Exploitation of the Vulnerable for Research Purposes}

Creating a categorical definition of exploitation is no less daunting a task in terms of precision than it was for vulnerability. Typical philosophical debates about exploitation struggle with differentiating exploitative interactions with just exchanges [17]. As with many issues of conceptual clarity, the more egregious examples are largely uncontested, but examples with more subtle gradations of inequity or injustice mesh indistinguishably with otherwise morally unobjectionable relationships. Some have drawn the conceptual boundary at beneficence, wherein relationships are 'zero-sum' ventures with the exploited losing and the exploiter gaining [18]. This winnertakes-all model is clearly exploitative in a research context, but it is relatively uncommon that clinical research excludes the research population from benefit, since research samples are often derived from populations with a specific need (in the case of medical research for example). This overly simplistic constitution of exploitation also plagues Allan Buchanan's work on the subject, wherein he draws a Kantian distinction between treating people as ends in themselves versus merely as means to the ends of others [19]. With a historical view of research exploitation, we have conduct that Buchanan's description fits, but to say that there will be no more modern-day Tuskegee's is not equivalent to stating that exploitation of research subjects has been extirpated.

A more sensitive treatment comes from Goodin, who elaborates the complex relationship between exploited and exploiter in his model. Goodin [6] offers a quartet of conditions which indicate to us that a relationship may be exploitative:

1) the relationship must be asymmetrical

2) the subordinate party must need the resource that the superordinate supplies

3) the subordinate party must depend upon some particular superordinate for the supply of needed resources

4) the superordinate enjoys discretionary control over the resources that the subordinate needs from him"

Goodin's construction speaks well to research. Much of the discussion around the modern exporting of research to poorer nations mires itself in our previously discussed issues of practical imperatives and balances of beneficence [20]. If we consider clinical research in developing nations, we can see that the elements of the asymmetrical relationship are present, and in the case of Human Immunodeficiency Virus (HIV) vaccine research in Africa and Southeast Asia, both the needs of the subordinates and the discretionary power over supply possessed by the superordinates is evident as well [21]. All of these factors precipitate exploitation, what actuates the moral issue is the abuse of said power. The mere existence of power imbalance is not exploitation, for if it were we should be shuttering all the programs offering assistance to the poor. Goodin's conditions, qua definitione, would apply to soup kitchens as much as it might to a major financial institution or clinical research program.

The active ethical ingredient in Goodin's formula is the necessity of superordinates to recognize that power begets obligation in equal proportions; with greater disparities of power comes an equal obligation to minimize the malfeasance that can often occur in such relations-either by desire or accident. For researchers, the issue is twofold; researchers should want to sensitize themselves to the possibility of accidental exploitation in their role as superordinate, and secondly, regulating bodies should enforce and regulate such relationships in the inevitable event that some researchers fail to act in a non-exploitative manner

\section{Conclusion}

Creating a definition of vulnerability that could accurately apply to a group of people is a transparent attempt at gentrified stereotyping. Furthermore, creating such stereotypes for the purposes of policy which would have direct impacts on peoples' lives is unconscionable. While the professed aim of such definitional miscreance is to protect a subpopulation is appropriate, the method of labeling those in need of protection rather than defining the misdeed is misguided. It is quite appropriate to define and label the wrongful behaviour as exploitation, and this is the more appropriate path for future debates of research ethics for the practicalities and normative considerations.

\section{References}

1. Lafleur WR, Bohme B, Shimazono S (2008) Dark Medicine: Rationalizing Unethical Medical Research., Indiana University Press, Bloomington.

2. Jonas H (1974) Philosophical reflections on experimenting with human subjects 
In: Jonas $\mathrm{H}$ (Ed) Philosophical Essays: From Ancient Creed to Technological Man. Prentice-Hall, Englewood Cliffs.

3. Inglefinger FJ (1972) Informed (But Uneducated) Consent. N Engl J Med 287: 465-466.

4. Rogers B (2000) Ethics and Research. AAOHN Journal 38: 581-585.

5. Kottow MH (2003) The Vulnerable and the Susceptible. Bioethics 17: 460-471.

6. Goodin R (1986) Protecting the Vulnerable: A Re-analysis of Our Social Responsibilities. University of Chicago Press, Chicago.

7. Silvers A (2004) Historical Vulnerability and Special Scrutiny: Precautions against Discrimination in Medical Research. Am J Bioeth 4: 56-57.

8. Kipnis K (2001) "Vulnerability in Research Subjects: A Bioethical Taxonomy. In: National Bioethics Advisory Committee (Eds) Ethical and Policy Issues in Research Involving Human Participants. Volume 2. National Bioethics Advisory Commission, Bethesda.

9. US Department of Health and Human Services (2009) Code of Federal Regulations. Title 45, Part 46, Protection of Human Subjects.

10. Canadian Institutes of Health Research, Natural Sciences and Engineering Research Council of Canada, Social Sciences and Humanities Research Council of Canada (2010) Tri-Council Policy Statement: Ethical Conduct for Research Involving Humans.

11. Council for International Organizations of Medical Sciences (CIOMS), World Health Organization (WHO) (2002) International ethical guidelines for biomedical research involving human subjects.
12. Levine C, Faden R, Grady C, Hammerschmidt D, Eckenwiler L, Sugarman J (2004) The Limitations of "Vulnerability" as a Protection for Human Research Participants. Am J Bioeth 4: 44-49.

13. Finder SG (2004) Vulnerability in Human Subject Research: Existential State, not Category Designation. Am J Bioeth 4: 68-70.

14. Hawkins JS, Emanuel JE (2005) Clarifying Confusions about Coercion. Hastings Center Report 35: 16-19.

15. Nelson RM, Beauchamp T, Miller VA, Reynolds W, Ittenbach RF, et al. (2011) The Concept of Voluntary Consent. Am J Bioeth 11: 6-16.

16. Emanuel EJ (2004) Ending Concerns About Undue Inducement. J Law Med Ethics 32: 100-105.

17. Wertheimer A (1996) Exploitation. Princeton University Press, Princeton.

18. Tormey J (1974) Exploitation, Oppression and Self-Sacrifice. Philosophical Forum 5: 206-221.

19. Buchanan A (1985) Ethics, Efficiency, and the Market. Rowman and Allanheld, Totowa.

20. Angell M (1997) The Ethics of Clinical Research in the Third World. N Engl J Med 337: 847-849.

21. Guenter D, Esparza J, Macklin R (2000) Ethical considerations in international HIV vaccine trials: summary of a consultative process conducted by the Joint United Nations Programme on HIVIAIDS (UNAIDS). J Med Ethics 26: 37-43. 